\title{
HACIA UNA JURISDICCIÓN MILITAR DEL SIGLO XXI. ALGUNAS PROPUESTAS PARA LA REFORMA DE LA JUSTICIA MILITAR ESPAÑOLA A LA LUZ DE LA JURISPRUDENCIA DEL TEDH
}

\section{A military jurisdiction for $21^{\text {st }}$ Century. Some proposals for military justice system's review in Spain in the light of ECHR case law}

\author{
FERNANDO GONZÁLEZ ALONSO \\ Cuerpo Jurídico Militar \\ fergonzalonso@hotmail.com
}

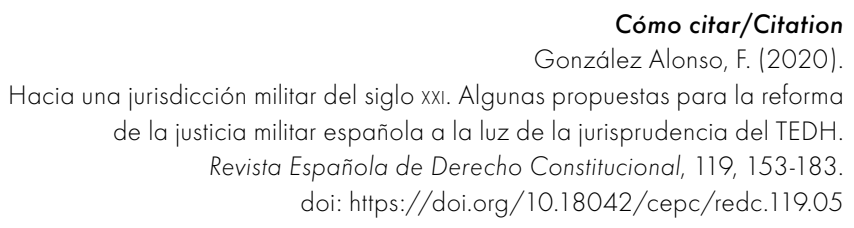

\section{Resumen}

Las sucesivas declaraciones del legislador referidas a la necesidad de acometer una reforma de la jurisdicción militar conducen a cuestionarse cuál haya de ser el concreto contenido de esta, en particular respecto de la organización y estatuto de quienes la ejercen.

Comenzando por el debate — reiterado, pero no agotado — acerca de la justificación de una jurisdicción militar diferenciada de lo que denominamos jurisdicción ordinaria, la segunda consideración a abordar es cuáles hayan de ser sus notas, y para ello se analizan algunos de los pronunciamientos que al respecto ha dictado el TEDH, que, considerado el art. 10.2 CE, habrán de inspirar el nuevo modelo que adoptar.

A la luz de lo anterior, el trabajo concluye apuntando un modelo que, a juicio del autor, concita las exigencias y garantías predicables de esa nueva jurisdicción militar. 


\title{
Palabras clave
}

Jurisdicción militar; órganos judiciales militares; derecho penal militar; jurisprudencia TEDH; independencia e imparcialidad judicial.

\begin{abstract}
Successive legislator's statements about the necessity of undertake a reform of military jurisdiction lead to ask which must to be the specific content of this jurisdiction, particularly about the organization and status of people who are involved in it.

Beginning with the debate - reiterated, but not extinguished — about the justification of a military jurisdiction different to we name ordinary jurisdiction, the second consideration to address is which will be its characteristics and for that it will be analysed the ECHR's case-law which, in the view of Article 10.2 of Spanish Constitution, will condition the new model to adopt.

In the light of foregoing, the work concludes pointing a model which, in the author's opinion, brings together the requirements and guaranties of that new military jurisdiction.
\end{abstract}

\section{Keywords}

Military jurisdiction; military courts; military criminal law; ECHR case law; independent and impartial courts. 


\section{SUMARIO}

I. INTRODUCCIÓN. LA NECESIDAD DE UNA REFORMA DE LA JURISDICCIÓN MILITAR ESPAÑOLA. II. ¿̇POR QUÉ UNA JURISDICCIÓN MILITAR?: 1. ¿¿Qué es una jurisdicción militar? 2. Concepciones doctrinales de la jurisdicción militar. 3. La postura del TC. 4. Justificación de la pervivencia de una jurisdicción militar en España. III. ALGUNOS APUNTES SOBRE LA JURISPRUDENCIA DEL TEDH REFERIDA A LAS JURISDICCIONES MILITARES: 1. La forma de designación de los miembros de los tribunales militares. 2. Duración del mandato de los miembros del órgano judicial. 3. Apreciación de garantías genéricas. 4. Independencia económica. 5. Organización interna. IV. A MODO DE PROPUESTA: UN MODELO DE JURISDICCIÓN MILITAR ESPAÑOLA ADECUADO A ESTOS POSTULADOS: 1. Elementos delimitadores del modelo de jurisdicción militar. 2. Principios caracterizadores de la jurisdicción militar. 3. Garantías de independencia e imparcialidad. 4. Propuestas para la adopción de un nuevo modelo de jurisdicción militar. BıBLIOGRAFíA.

\section{INTRODUCCIÓN. LA NECESIDAD DE UNA REFORMA DE LA JURISDICCIÓN MILITAR ESPAÑOLA}

La reforma de la jurisdicción militar comienza a ser, atendiendo a las palabras del propio legislador, una tarea perentoria. Así, el apartado 3 de la disposición final octava de la Ley Orgánica 9/2011, de 27 de julio, de derechos y deberes de los miembros de las Fuerzas Armadas, señalaba la necesidad de actualizar el Código Penal Militar y «realizar las necesarias adaptaciones de las leyes procesales militares», y cuatro años después, tanto la Ley Orgánica 7/2015, de 21 de julio, de reforma de la LOPJ, como la Ley Orgánica 14/2015, de 14 de noviembre, del Código Penal Militar (CPM), insistían en la necesidad de abordar la reforma de la Ley Orgánica 4/1987, de 15 de julio, de la Competencia y Organización de la Jurisdicción Militar (LOCOJM), ahora fijando un término para la remisión del proyecto de ley, que no ha sido cumplido. No obstante, es evidente que una reforma del calado de la que aquí se propondrá exigiría también una profunda revisión de la Ley Orgánica 2/1989, de 13 de abril, Procesal Militar (LOPM).

Tal reforma pretendía enmarcarse en una revisión conjunta de las leyes penales y disciplinarias militares, pero, aprobada la del derecho sustantivo sin el esperado consenso de las fuerzas políticas, desembocó en obra inacabada una vez desaparecida la mayoría absoluta en el Legislativo. La justificación de esa ambiciosa reforma de conjunto residía — extractando lo expuesto en el 
preámbulo del referido CPM-, en primer lugar, en el tiempo transcurrido desde la promulgación de las leyes que reformar, con lo que ha supuesto de profesionalización de las Fuerzas Armadas, nuevo modelo organizativo y de despliegue territorial de la fuerza, la permanente participación en misiones internacionales y la integración en unidades multinacionales u organizaciones supranacionales, pero también en la necesidad de perfilar el ámbito de lo estrictamente castrense y dar cumplimiento a las obligaciones asumidas por España en el marco del derecho internacional. Razones a las que han de sumarse, a mi juicio, otras que más adelante se expondrán.

La pretensión de este trabajo es apuntar cuál pueda ser la reforma que ha de abordarse en torno a la organización de la jurisdicción militar en Espańa, analizando previamente si esta es necesaria y cuáles pueden ser las premisas que impone al respecto la jurisprudencia del TEDH. No trato de sentar tesis irrefutables — si acaso es posible en derecho-, sino precisamente lo contrario: suscitar un debate por parte de los operadores afectados. Especialmente, los militares (incluidos, obviamente, en su condición de tales, los miembros de la Guardia Civil), a través de las vías institucionalmente reconocidas, deben contribuir al diseño de ese nuevo marco jurisdiccional; también las personas que intervienen en la Administración de justicia militar, singularmente, los abogados especializados en la materia; los estudiosos de esta rama del derecho, tales como profesores universitarios o jueces y fiscales de la jurisdicción ordinaria, y, necesariamente, los miembros del Cuerpo Jurídico Militar que, dada su condición, formación y experiencia, podrán aportar elementos de juicio esenciales. La amplitud de ese debate determinará el alcance y calidad de los argumentos y criterios de que puedan valerse los encargados de la adopción de los textos legales pertinentes.

\section{II. ¿ ¿POR QUÉ UNA JURISDICCIÓN MILITAR?}

Seguramente no serán pocos los que antes de plantearse el modelo de jurisdicción militar que ha de adoptarse se pregunten si esta es necesaria.

\section{1. ¿QQUÉ ES UNA JURISDICCIÓN MILITAR?}

Antes de abordar la necesidad de dicha jurisdicción veo preciso atender a otra consideración que por su aparente obviedad quizá sea pasada por alto con demasiada frecuencia. Se trata de definir qué es una jurisdicción militar. Así, Jiménez Villarejo (1989: I2) señala que «la justicia militar sería, pues, la 
propia de un "cuerpo", netamente diferenciado dentro del conjunto social en que coexistirían, rígidamente jerarquizados y sólo relativamente cohesionados, una pluralidad de grupos y estamentos».

Según la STEDH de 22 de octubre de 1984, caso Sramek contra Austria, un «Tribunal» se caracteriza, en el sentido material, por su función jurisdiccional, «le corresponde decidir, sobre la base de normas jurídicas y conforme a un procedimiento preestablecido, toda cuestión dependiente de su competencia $»^{1}$. y considera como tribunales militares todos aquellos que total o parcialmente se integran por miembros de las Fuerzas Armadas ${ }^{2}$, lo cual, pese a su aparente obviedad, constituye una conceptuación relevante. En el mismo sentido parece posicionarse Pérez Esteban (1999: 518) cuando señala que «esta es una circunstancia básica de la jurisdicción militar: que se ejerce de manera permanente por militares pertenecientes al Cuerpo Jurídico Militar». Y es que, bajo tal definición, hablar de una jurisdicción militar como un orden jurisdiccional más, sería una contradicción, pues se trataría entonces de un orden especializado, pero no de una jurisdicción como tal. Cuestión distinta es si nuestra Constitución admite esa posibilidad o cualquier otra fórmula que implique prescindir de una jurisdicción militar, asunto sobre el que volveré más adelante.

\section{CONCEPCIONES DOCTRINALES DE LA JURISDICCIÓN MILITAR}

La justificación de la existencia misma de la jurisdicción militar — también de su configuración - se ha vinculado a la definición de las Fuerzas Armadas, la cual, a su vez, debe establecerse necesariamente desde la previa determinación de la naturaleza constitucional de estas. Siguiendo para ello al profesor Canosa Usera (1994: 7):

Se nos presentan, pues, tres hipótesis a la hora de captar la esencia de las FF. AA.: En la primera se tratarían de un poder distinto y autónomo del civil, en la segunda, de una institución garantizada por la Constitución, y, en la tercera, las FF. AA. son, llanamente, administración del Estado. Las muy distintas maneras de concebir jurídicamente los Ejércitos conducen a modelos de justicia militar también diversos. Las tres posiciones esbozadas cuentan, en opinión de sus respectivos defensores, con apoyaturas constitucionales.

1 En el mismo sentido, STEDH de 28 de junio de 1984, caso Campbell y Fell contra Reino Unido, ap. 76.

2 SSTEDH de 26 de febrero de 2002, caso Morris contra Reino Unido, o de 1 de septiembre de 2016, caso Svitlana Atamanyuk y otros contra Ucrania. 
La segunda postura, defendida, entre otros, por Jiménez Villarejo (1989: 13), sin cuestionar la subordinación funcional de los ejércitos al poder civil, considera las Fuerzas Armadas como una institución, de acuerdo con las teorías institucionalistas del derecho acuñadas a partir de las tesis de Santi Romano (2013) o Hauriou (1976). Así, para Higuera Guimerá (1990: 22) las Fuerzas Armadas «constituyen y son una Institución de relevancia constitucional ya que no pueden ser suprimidas, y en algún caso ni siquiera reformadas, en todo o en parte, si no es mediante una ley de reforma constitucional». De igual modo las califica López Garrido (1983: 957), entendiendo, además, que «están protegidas constitucionalmente mediante la técnica de la garantía institucional» (1983: 959).

Finalmente, puede defenderse que las Fuerzas Armadas no son sino Administración del Estado. Si se quiere, con mayores rasgos identificativos o singulares, pero de igual naturaleza. Esta postura es la defendida por autores como López Ramón (1987), Barcelona Llop (1986), Blanquer Criado (1996) o el propio Canosa Usera (1994).

En relación con el primer planteamiento, convengo con Canosa Usera en que ni la preeminente ubicación del art. $8 \mathrm{CE}$, ni la atribución al rey de la jefatura suprema de los ejércitos, ni la diferenciación entre las funciones del Gobierno de dirección de la Administración civil y militar y defensa del Estado, que establece el art. $97 \mathrm{CE}$, constituyen argumentos suficientes para sostener un papel autónomo de las Fuerzas Armadas al margen de la voluntad del Poder Legislativo y Ejecutivo.

Tanto la tesis institucionalista como la administrativista aportan argumentos jurídicamente firmes, pero considero que la $\mathrm{CE}$ no determina una concreta forma de Fuerzas Armadas ni las configura con un carácter unívoco. Como sucede con muchos aspectos de nuestra Carta Magna, se trata de un texto abierto que faculta al Poder Legislativo para establecer diferentes configuraciones de distintas instituciones; las Fuerzas Armadas y la jurisdicción militar son ejemplo de ello. En este sentido, para Fernández Segado (1992: I2), la existencia de la jurisdicción militar:

[...] constituye una singularidad jurisdiccional de relevancia constitucional, singularidad que se traduce en el hecho de que, como ha reconocido el Juez de la Constitución, la jurisdicción castrense no puede organizarse sin tener en cuenta determinadas peculiaridades que originan diferencias tanto sustantivas como procesales respecto de la jurisdicción ordinaria. Estas especialidades, como asimismo el propio reconocimiento constitucional de la jurisdicción militar, son a su vez la obligada consecuencia de la peculiar configuración que deben revestir las Fuerzas Armadas a fin de poder cumplir con eficacia los altos fines que les asigna el artículo $8^{\circ}$ de la Constitución. 
Mientras, Pérez Esteban (1999: 511) considera que estas peculiaridades «desembocan en la organización de la jurisdicción militar, cuyo concreto contenido no está fijado, desde luego, de manera indisponible en la propia Constitución, aunque ésta garantiza en el artículo 117.5 su preservación en términos recognoscibles para la imagen que de la misma tiene la conciencia social en cada tiempo y lugar $\aleph^{3}$.

En contra de su existencia se manifiesta, por ejemplo, López Lorca (2011: 6), afirmando que «la actual configuración de la justicia militar ha dejado -o debido dejar- atrás argumentos como los hasta ahora indicados - especialidad de la materia, apreciación de los valores militares, estructura autónoma de las Fuerzas Armadas o constante histórica-, los cuales revelan que su existencia o inexistencia aparece ligada a criterios de oportunidad histórico-políticos más que a razones de fondo o materiales». Considero que los argumentos enunciados evidencian precisamente los rasgos singulares a que se refiere la tesis institucionalista, e incluso la administrativista, sin perjuicio de la confluencia con criterios de oportunidad.

\section{LA POSTURA DEL TC}

Sin que la extensión de este estudio permita un análisis exhaustivo, ya la STC 180/1985, de 19 de diciembre, reconocía la constitucionalidad de las peculiaridades organizativas y procesales de la jurisdicción militar en atención a los fines de las Fuerzas Armadas, al señalar:

[...] jurisdicción militar (art. 117.5 de la Constitución) no puede organizarse sin tener en cuenta determinadas peculiaridades que originan diferencias tanto sustantivas como procesales, que, si dispuestas en el respeto a las garantías del justiciable y del condenado previstas en la Constitución, no resultarán contradictorias con su artículo 14 cuando respondan a la naturaleza propia de la institución militar. Estas peculiaridades del Derecho Penal y Procesal Militar resultan genéricamente, como se declaró en la Sentencia 97/1985, de 29 de julio (fundamento jurídico 4. ${ }^{\circ}$ ), de la organización profundamente jerarquizada del Ejército, en el que la unidad y disciplina desempeñan un papel crucial para alcanzar los fines encomendados a la institución por el art. 8 de la Constitución.

3 Esta última nota de la recognoscibilidad en cada tiempo y lugar es la que el TC atribuye a las denominadas «garantías institucionales» (SSTC 32/1981, de 28 de julio, y 26/1987, de 27 de febrero). 
A lo que posteriormente —entre otras, en las SSTC 204/1994, de 11 de julio, y 113/1995, de 6 de julio— añadía que «más allá de todas sus peculiaridades reiteradamente reconocidas por este Tribunal (STC 97/1985, fundamento jurídico $4 .^{\circ} ; 180 / 1985$, fundamento jurídico $2 . .^{\circ} ; 60 / 1991$, fundamento jurídico $4^{\circ}$ ) ha de ser "jurisdicción", es decir, ha de ser manifestación de la función constitucional a la que, como derecho fundamental, se confía la tutela judicial efectiva» o, de otro modo, "tal diferencia de régimen jurídico no afecta ni compromete el derecho a la tutela judicial efectiva sin indefensión» (STC 202/2002, de 28 de octubre).

En relación con ese equilibrio entre la salvaguarda de la tutela judicial efectiva y el elemento prototípico de la organización militar, decía la STC 115/2001:

[...] no cabe cuestionar que la disciplina es un valor imprescindible en toda organización jerarquizada que, en el caso de las Fuerzas Armadas, se convierte en un ineludible principio configurador, sin cuya garantía y protección se dificulta el cumplimiento de los cometidos que constitucional y legalmente tienen asignados por el art. 8.1 CE. Por ello, si bien la particular relación de sujeción especial en que se encuentran los militares no puede ser aducida como fundamento para justificar toda limitación al ejercicio de sus derechos fundamentales, no cabe considerar contrarias a dichos derechos, aquellas disposiciones legales limitativas de su ejercicio que resulten estrictamente indispensables para el cumplimiento de su misión (SSTC 21/1981, de 15 de junio, F. 15, y 31/2000, de 3 de febrero, F. 4), entre las que, indudablemente, han de situarse todas las que sean absolutamente imprescindibles para salvaguardar ese valor esencial en toda institución militar, que es la disciplina.

Sin embargo, tal sentencia otorgó el amparo a un guardia civil que, en virtud de lo dispuesto en los arts. 108.2 LOCOJM y 127.1 LOPM, había visto rechazada ante la jurisdicción militar la posibilidad de ejercitar la acusación particular frente a un superior jerárquico de su misma unidad, planteando autocuestión de inconstitucionalidad respecto a esos preceptos cuya inconstitucionalidad declararía la STC 179/2004, de 21 de octubre.

\section{JUSTIFICACIÓN DE LA PERVIVENCIA DE UNA JURISDICCIÓN MILITAR EN ESPAÑA}

A mi juicio, el art. 117.5 CE no establece la existencia de una jurisdicción militar de forma imperativa, sino que, acorde con ese carácter abierto al que 
se ha hecho referencia, contempla su posible existencia ${ }^{4}$. No considero que pueda hablarse de una garantía institucional, pues no se trata de un elemento arquitectural indispensable del orden constitucional —en palabras de la STC 32/1981 - . Aun cuando la redacción emplea un término imperativo — «la ley regulará el ejercicio de la jurisdicción militar»—, cabe interpretar tal imperatividad para el caso de que el legislador opte por contemplar una jurisdicción militar específica, como excepción al principio de unidad jurisdiccional que se proclama en ese mismo precepto y sometiéndola, en todo caso, a dos condiciones insoslayables: que su actuación se adecúe a los principios constitucionales y que se limite al ámbito de lo estrictamente castrense.

Más allá de posiciones asentadas en uno u otro extremo - supresión o existencia ineludible-, amparadas en argumentaciones profundamente teóricas, considero que la configuración de una jurisdicción militar como tal quedaría justificada por las innegables aportaciones de eficiencia que implica tanto desde el punto de vista de organización de los poderes del Estado como del propio justiciable. Como personal vinculado por una relación de especial sujeción ${ }^{5}$, el militar debiera preferir que el enjuiciamiento de conductas que se refieran a los elementos determinantes de esa relación recaiga en individuos especialmente capacitados tanto técnica como profesionalmente. Además, aquí no solo se exige un conocimiento jurídico específico, sino la consideración de una serie de valores que no son siempre comunes a la sociedad en su conjunto, lo que debiera hacer valorable que quienes administren esta justicia tengan un contacto directo con la realidad castrense. Ello no debe ser óbice para garantizar con total plenitud la independencia que ha de caracterizar a todo órgano judicial, así como el resto de principios que permitan hablar de una verdadera jurisdicción. Si el argumento para eliminar la jurisdicción militar es su falta de garantías, ¿no sería más oportuno dotarla de tales garantías?

4 Fernández Segado (1992: 11 y 12) señala: «Creemos que no nos hallamos ante una institución que pueda considerarse componente esencial del orden jurídico-político establecido por la Constitución, cuya preservación se juzgue indispensable para asegurar los principios constitucionales; consecuentemente, no pensamos que pueda sostenerse que existe en esta institución un núcleo o reducto indisponible para el legislador». También resulta potestativa la existencia de una jurisdicción militar a la vista del texto constitucional para, entre otros, Mozo Seoane (1995: 629), Gil García (1999: 60), Doig Díaz (2003: 215-224) o López Lorca (2011: 4).

5 Las implicaciones que la condición de militar implica sobre los derechos y libertades fundamentales han sido ampliamente analizadas, pudiendo destacar los estudios de Blanquer Criado (1996), González Reyes (2011) o Fernández García (2015). 
Por otro lado, la escasa relevancia cuantitativa de muchos de los asuntos propios de la jurisdicción militar o del ámbito jurídico castrense - especialmente del penal- exige que exista un cuerpo profesional que lleve a cabo la exégesis de dicho derecho y que se encuentre doctrinalmente preparado para su aplicación práctica cuando sea preciso. Es decir, no puede valorarse la necesidad de una jurisdicción militar en términos meramente cuantitativos, sino también en términos cualitativos. Lo que aquí está en juego es la tutela judicial efectiva de un colectivo dispuesto a entregar su vida en defensa de los intereses nacionales y la salvaguarda de bienes jurídicos de suma relevancia. No obstante, asegurada la independencia e imparcialidad de los órganos judiciales militares, nada obstaría a otorgarle nuevas competencias, dentro, eso sí, del ámbito de lo estrictamente castrense.

Justificada su existencia en esa adecuación a la tutela judicial que se pretende y al conocimiento del específico derecho que ha de aplicar, dos son, a mi modo de ver, los principios o elementos diferenciales que deben regir la configuración de la jurisdicción militar: la existencia de un código de conducta propio marcado por una serie de valores que hacen identificable a la institución como tal (unidad, disciplina, jerarquía, valor, honor...), y, vinculado a lo anterior, el cumplimiento de una serie de misiones, también únicas, con arreglo a esas reglas de comportamiento. Estos elementos y su vinculación a valores y principios constitucionales ampararían, atendiendo a la citada jurisprudencia del TC, una particular configuración de la jurisdicción militar.

El primero de estos elementos conduce a la necesidad de que la jurisdicción militar esté servida por miembros de las Fuerzas Armadas. La consideración de bienes jurídicos específicos requiere de la participación de ciertos valores que son propios de la institución y diferentes - al menos en su intensidad - de los de la sociedad en general. La conducta del enjuiciado por un delito militar no puede ser apreciada bajo los mismos cánones que rigen en el derecho penal común en cuestiones tales como el miedo insuperable, la obediencia debida, la exigibilidad de una conducta distinta o la asunción del riesgo ${ }^{6}$. Ya señalé, por otro lado, que la definición misma de jurisdicción militar conlleva su composición —al menos en parte- por miembros de las Fuerzas Armadas.

Por otro lado, las Fuerzas Armadas se caracterizan por las misiones que están llamadas a cumplir. Señala el Concepto de Empleo de las Fuerzas Armadas (Secretaría del Jefe de Estado Mayor de la Defensa, 2017) como características de la Fuerza Conjunta: «[...] la adecuación, alta disponibilidad, versatilidad, eficiencia, carácter expedicionario y resiliencia». Tales características exigen

6 Por ejemplo, Juanes Peces (2014: 170-172). 
una configuración de dicha jurisdicción — tanto en su dimensión orgánica como funcional - que satisfaga esas notas. Es decir, debe tratarse de una jurisdicción que, aún en mayor medida que la ordinaria, actúe marcada por la capacidad de disposición y adaptación a situaciones derivadas de las misiones militares, tanto en el territorio nacional como fuera de él, y ello no puede lograrse con una mera proclamación normativa, sino que exige una regulación de los procedimientos, así como una organización y disposición de medios materiales y humanos, adecuados a tal fin.

\section{ALGUNOS APUNTES SOBRE LA JURISPRUDENCIA DEL TEDH REFERIDA A LAS JURISDICCIONES MILITARES}

Tanto la obligación que impone el art. 10.2 CE como la constatable incidencia de la doctrina del Tribunal de Estrasburgo sobre las jurisprudencias del $\mathrm{TC}^{7}$ y del TS ponen de manifiesto la relevancia de su consideración para el propósito de este trabajo. Buen ejemplo de las implicaciones de la jurisprudencia del TEDH en esta materia es la reforma que el Reino Unido operó en su sistema de courts martial debido a las sucesivas estimaciones de recursos por vulneración del art. 6.1 $\mathrm{CEDH}^{8}$. Por ello, considero imprescindible que la

$\mathrm{Al}$ respecto, resulta particularmente enriquecedora la tesis presentada en la Universidad de Valencia por D. Alejandro Catalá Bas (1999), o el trabajo de Martín-Retortillo Baquer (1995).

8 El sistema de courts martial que regía en virtud tanto de la Army Act de 1955 como de la Naval Discipline Act de 1957 y la Air Force Act de 1955 fue declarado incompatible con el CEDH por la STEDH de 25 de febrero de 1997, caso Findlay contra Reino Unido, y otras posteriores. Concretamente, en relación con la Royal Army: SSTEDH de 18 de febrero de 1999, caso Hood; de 29 de septiembre de 1999, caso Smith y Ford, y de 6 de febrero de 2001, caso Wilkinson y Allen. Respecto a la Royal Air Force: de 18 de febrero de 1999, caso Cable y otros; de 24 de septiembre de 1997, caso Coyne, y de 29 de septiembre de 1999, caso Moore y Gordon. Y en cuanto a la Royal Navy: de 15 de junio de 2004, caso Le Petity G. W., todas ellas contra el Reino Unido.

La Armed Forces Act de 1996 entró en vigor el 1 de abril de 1997 y modificó ciertas disposiciones de las normas citadas en lo relativo al sistema judicial militar británico. Tras dicha reforma el TEDH entró a valorar nuevamente, por primera vez en el caso Morris contra Reino Unido, la adecuación al CEDH del mencionado sistema judicial militar británico.

Para el estudio de estas cuestiones resulta particularmente ilustrativo el estudio de Lorenzo Ponce de León (2008). 
reforma a abordar parta de una consideración inequívoca de los postulados establecidos por el TEDH.

A modo de compendio, y atendidas su proximidad temporal y relevancia fáctica, considero merecedora de mención la STEDH de 1 de septiembre de 2016, caso Svitlana Atamanyuk y otros contra Ucrania ${ }^{9}$, en la que, de forma sintética, se establecen los elementos determinantes de la independencia de los tribunales militares, al señalar:

[...] la calidad del procedimiento por el que se rigen los tribunales militares, en particular el carácter confidencial de sus deliberaciones y la posibilidad de revisión por un tribunal ordinario, la disposición de una formación adecuada para los militares involucrados en la resolución de asuntos; el modo de su nombramiento, ascenso y régimen disciplinario (en particular, si tales oficiales permanecen sometidos a informes de evaluación militar y si tales informes pueden evaluar la calidad de sus decisiones judiciales), y otros elementos.

Trataré de analizar separadamente algunos de estos elementos.

\section{FORMA DE DESIGNACIÓN DE LOS MIEMBROS DE TRIBUNALES MILITARES}

Aún en pronunciamientos no referidos expresamente a tribunales militares, resulta reiterada la doctrina del TEDH (entre otras, SSTEDH de 29 de abril de 1988, caso Belilos contra Suiza; de 28 de junio de 1984, caso Campbell y Fell contra Reino Unido, o de 22 de octubre de 1984, caso Sramek contra Austria) que señala que la mera designación de los componentes de un tribunal por parte del Poder Ejecutivo no es sinónimo, por sí sola, de falta de independencia, si ello no se traduce en una posibilidad de dirigirle instrucciones vinculantes y obligatorias. La cuestión determinante será si esa vinculación se manifiesta en el momento del ejercicio de la jurisdicción.

En referencia a esa forma de designación, pero relacionada con el estatuto de los miembros de un tribunal militar, la STEDH de 26 de febrero de 2002, caso Morris contra Reino Unido, analiza el modo de nombramiento de los dos oficiales

9 Se trata del enjuiciamiento acerca de la adecuación al CEDH de la investigación y el proceso judicial seguido en Ucrania contra los responsables de la caída de una aeronave militar durante el desarrollo de un festival aéreo en el aeródromo de Sknyliv, el 27 de julio de 2002, a consecuencia del cual fallecieron 77 personas y cerca de 300 resultaron heridas, y que derivó, entre otras actuaciones, en el enjuiciamiento de varios altos cargos del Ejército del Aire ucraniano, entre ellos, su mando superior. 
que, junto con un presidente permanente, constituían la court martial. Esos miembros ordinarios no eran designados para un concreto período de tiempo, sino más bien con una consideración ad hoc, con el conocimiento de que regresarían a sus destinos militares al final del proceso. Ello no resulta, por sí solo, incompatible con los requisitos de independencia, pero sí conlleva la necesidad de que existan garantías contra cualquier clase de presión externa, y aprecia como tales garantías la presencia de un judge advocate civil como miembro asesor de la court martial en materia legal o la existencia de un presidente permanente.

\section{DURACIÓN DEL MANDATO DE LOS MIEMBROS DEL ÓRGANO JUDICIAL}

El TEDH ha reiterado la idea de que, pese a que la inamovilidad de los jueces debe ser considerada generalmente como corolario de su independencia, la ausencia de un reconocimiento formal de esta en la ley no implica, por sí sola, una quiebra de la independencia, siempre y cuando esta sea reconocida de hecho y existan otras garantías necesarias (véase Campbell y Fell contra Reino Unido, ya citada, ap. 80). Por ello, en el comentado caso Morris destaca el carácter permanente de su presidente, al señalar (ap. 69):

[...] la presencia de dicho presidente no cuestiona la independencia del tribunal, más bien, la duración de su cargo y la seguridad de facto de su mandato, el hecho de que obviamente no tenga preocupaciones por su promoción o ascenso militar y que no esté sometido a informes sobre su carrera, así como su relativa separación de la estructura de mando militar, implica que tiene una significativa garantía de independencia a diferencia de un tribunal ad hoc.

Ello asemejaba su posición a la de los miembros militares de la Dutch Supreme Military Court, cuya independencia e imparcialidad había sido declarada en el caso Engel ${ }^{10}$.

\section{APRECIACIÓN DE GARANTÍAS GENÉRICAS DE INDEPENDENCIA}

A través de la apreciación de estas garantías genéricas el TEDH lleva a cabo una valoración de conjunto acerca de la independencia e imparcialidad de los órganos judiciales. Los pronunciamientos referidos específicamente a

10 STEDH de 8 de junio de 1976, caso Engel y otros contra Países Bajos, apdos. 30, 68 y 89. 
tribunales castrenses han considerado, entre estas garantías genéricas, cuestiones como el estatuto jurídico de los componentes del tribunal, su organización interna o la distribución de cometidos entre sus miembros.

En relación con el estatuto jurídico, el caso Morris señalaba respecto de los miembros ordinarios de la court martial «que esos oficiales no tenían preparación jurídica, permanecían sujetos a la disciplina militar y a informes profesionales y no existía un estatuto o prohibición que impidiera su influencia externa durante su función en el tribunal». Además, otorga especial relevancia al hecho de que la acusación se refiere a una conculcación de la disciplina militar, pues en tales casos los miembros militares del tribunal no pueden ser comparados con los integrantes de un jurado civil, quienes no están sometidos a ese riesgo de presión.

Sin embargo, la STEDH de 16 de diciembre de 2003, caso Cooper contra Reino Unido, dictada por la Gran Sala, en relación con una court martial idéntica a la del caso Morris, adoptó la decisión opuesta. El argumento para ese cambio se basó en una serie de consideraciones no apreciadas en el caso Morris por falta de invocación del Gobierno británico. En primer lugar, la entrega a los miembros ordinarios del órgano judicial, por parte del órgano encargado de su designación, de unas notas explicativas de las fases del proceso, sus funciones y límites como miembros de ese órgano y una completa información sobre su obligación de desarrollar la función de manera independiente, así como pautas que seguir en el caso de ver afectada su independencia. En segundo lugar, alegó el Gobierno británico que los informes anuales emitidos a dichos oficiales no se referían a su toma de decisiones como miembros del tribunal, teniendo prohibido informar o hacer comentarios sobre lo discutido y votado.

Siendo idénticas las restantes circunstancias, parece irrisorio que la falta de conocimiento jurídico de los miembros ordinarios de la court martial, apreciada en el caso Morris como elemento determinante de la quiebra de la independencia e imparcialidad, pueda estimarse ahora superada por la simple distribución de las notas descritas. Por otra parte, respecto a los informes anuales, aun cuando estos no tuvieran expresamente esa función, indudablemente podían condicionar la labor jurisdiccional de esos oficiales, pues se pasa por alto la más importante de las apreciaciones al respecto en el caso Svitlana, que no es otra que esos miembros ordinarios de la court martial seguían - antes, durante y después del desempeño de esa función- sometidos a disciplina militar, integrados en una cadena de mando, y retornaban a sus funciones militares ordinarias una vez finalizada su tarea temporal en el órgano judicial.

Por contra, la STEDH de 16 de diciembre de 2003, caso Grieves contra Reino Unido, también dictada por la Gran Sala, apreció la conculcación del 
art. 6.1 CEDH. La decisión se debió a las particularidades que la Royal Navy, a la que pertenecía la court martial en cuestión, había mantenido en la configuración de estos órganos. En primer lugar, el presidente no tenía carácter permanente, seguía sujeto a expectativas de destinos o ascensos y sometido a la valoración de sus funciones. Además, el judge advocate, a diferencia de lo que sucedía en los otros ejércitos, tenía condición de militar y, aunque era seleccionado de manera permanente para ese puesto, compatibilizaba las funciones con las ordinarias de un destino puramente militar. Frente a la invocada mejor adecuación de estos oficiales al lenguaje y tradiciones de la Royal Navy, considera el TEDH que la función del judge advocate es asesorar sobre aspectos legales que no precisan esa adecuación y sí, por el contrario, conocimientos jurídicos.

\section{INDEPENDENCIA ECONÓMICA}

La STEDH de 27 de noviembre de 2008, caso Miroshnik contra Ucrania, aunque alude a la condición militar de los jueces que integran los tribunales militares y su consiguiente subordinación al Ministerio de Defensa, incorpora como criterio novedoso la afectación a la independencia e imparcialidad de esos órganos de ciertas condiciones socioeconómicas de sus miembros. Así, el hecho de que correspondiese al Ministerio de Defensa proveer a estos jueces de una vivienda en el caso de que lo precisasen y que fueran los órganos de dicho ministerio los que gestionaban de facto la financiación, logística y mantenimiento de los tribunales militares, pese a que no era su competencia decidir la aportación anual económica para estas cuestiones - que correspondía al Ministerio de Justicia y al Tribunal Supremo en la cuantía fijada en los presupuestos estatales-. Para el TEDH, estos aspectos del estatuto de los jueces militares, valorados conjuntamente, otorgaban al recurrente motivos objetivamente justificados para dudar de su independencia e imparcialidad.

\section{ORGANIZACIÓN INTERNA}

Otro de los aspectos que ha sido objeto de consideración por varias SSTEDH respecto a la independencia es el de la organización interna de los tribunales castrenses y las atribuciones que corresponden a cada uno de los intervinientes en el proceso. Como ejemplo puede citarse la STEDH de 25 de febrero de 1997, caso Findlay contra el Reino Unido, en la que el TEDH estimó objetivamente fundadas las dudas planteadas por el recurrente acerca de la 
independencia e imparcialidad de los miembros de la court martial atendiendo fundamentalmente al papel desempeñado por el denominado convening officer. Dicho oficial asumía importantísimas funciones, como, por ejemplo, decidir la naturaleza y el detalle de las acusaciones, convocar la court martial o designar a los restantes miembros del tribunal. Debía prestar su consentimiento para que se retiraran ciertos cargos contra el acusado o para admitir el beneficio de circunstancias atenuantes solicitado por el procesado. Era el encargado de facilitar al procesado una adecuada preparación de su defensa, mediante un representante si fuera necesario y el contacto con los testigos de descargo, ordenando su comparecencia cuando era "razonablemente requerida» por la defensa. También podía disolver la court martial antes o durante el proceso. Ese papel del convening officer convertía - a juicio del TEDH - la consideración de otras garantías en insuficientes para apreciar la necesaria independencia e imparcialidad del órgano.

\section{A MODO DE PROPUESTA: UN MODELO DE JURISDICCIÓN MILITAR ESPAÑOLA ADECUADO A ESTOS POSTULADOS}

\section{ELEMENTOS DELIMITADORES DEL MODELO DE JURISDICCIÓN MILITAR}

Como ha quedado expuesto, dentro del margen del legislador para configurar la jurisdicción militar existen dos elementos condicionantes establecidos por el art. 117.5 CE: limitación de su actuación al ámbito estrictamente castrense y sujeción a los principios constitucionales.

En relación con el primero de ellos, aun cuando doctrina y jurisprudencia se han adentrado con profusión en el análisis de esta cuestión —en la que no cabe detenerse aquí-, convengo con Canosa Usera (1994: 4) en que se trata de un "concepto jurídico indeterminado que debe concretar el legislador», sin perjuicio de que surjan en la práctica supuestos ciertamente complejos ${ }^{11}$.

Considero de mayor trascendencia la segunda de las premisas. La valoración de la jurisdicción militar debe hacerse, como ya anticipé, desde los elementos que permitan identificarla como auténtica jurisdicción. Como señala Doig Díaz

11 También Alaiz Villafáfila (1992: 6) parece sostener esa idea cuando señala: «[...] parece que a la jurisdicción militar habrá de darse la atribución sobre el ámbito estrictamente castrense (según delimitación del mismo por el legislador previa, fuera muy conveniente, consulta con los propios militares); sin embargo lo que parece venir haciendo el legislador, a remolque del devenir social y utilizando para ello la composición de los códigos penales, común y militar, es repartir ese ámbito entre ambas jurisdicciones de forma voluble». 
(2003: 63) en su prolijo estudio sobre la jurisdicción militar española, siguiendo a Fairén Guillén (1972: 56), el concepto de jurisdicción se basa en tres aspectos: naturaleza jurídica, función y estructura, aseverando que "todos y cada uno de los elementos que componen la jurisdicción deben estar presentes en la jurisdicción militar para poder conceptuarla, efectivamente, como jurisdicción». El problema ciertamente se produce a la hora de establecer en qué medida deben observarse. Si dichos principios son observados en la misma medida que en los órganos jurisdiccionales ordinarios, el debate acerca de lo estrictamente castrense pierde su virtualidad, pues haría fútil la distinción. Tal afirmación puede conducir a dos alternativas: si el constituyente ha querido establecer una delimitación competencial de la jurisdicción militar es porque asume una diferente salvaguarda de los principios constitucionales que lo observado en la jurisdicción ordinaria, o que tal delimitación carece de relevancia puesto que lo verdaderamente necesario es que la jurisdicción militar, aun siendo identificable como tal, observe esos principios. Esta segunda postura es la que considero preeminente, si bien pueden existir elementos en los que resulte admisible una atemperación de los principios constitucionales, y de ahí la necesaria delimitación competencial.

A la hora de evaluar la observancia de los principios y postulados que convierten a una jurisdicción en tal, coincido con Escalada López (2007: 2) en lo siguiente:

[...] la referencia del art. 117.1 CE, no ha de entenderse realizada al «poder» judicial organización — referido al conjunto de órganos y de jueces regulados en y por la LOPJ - ya que, lo contrario, supondría excluir de dicha fórmula a los magistrados que componen los órganos orgánicamente especiales; tampoco lo es al "poder» judicial competencia-procesal —en alusión a los órganos y jueces dotados de competencia general y atrayente— pues, de ser así, quedarían excluidos los jueces integrantes de los órganos competencialmente especiales, sino que la mención lo es al "poder» judicial jurisdicción —identificado con los órganos y jueces dotados de independencia, precisamente, por su constitucional creación y atribución de potestad jurisdiccional y por su legal distribución de competencia procesal-. Esto último significa, que lo que realmente se exige de los jueces y magistrados es que, de las notas que informan el estatuto al que están sujetos, se deduzca y posibilite su independencia, instrumentalmente avalada por la inamovilidad, recíprocamente contraprestada por su responsabilidad y teleológicamente alcanzada por su efectiva sumisión a la ley.

No en vano, las principales críticas que en nuestros días recibe la jurisdicción militar no son relativas a su ámbito competencial, sino al estatuto jurídico de sus integrantes. Así lo expresan autores como Gimeno Sendra, Moreno 
Catena y Cortés Domínguez (2003: 63-67), Canosa Usera (1995: 351) o Escalada López (2007: 15), señalando, por ejemplo, esta última, que, «aunque la legislación militar garantiza formalmente su independencia e inamovilidad - en referencia a quienes componen la jurisdicción militar-, las cuestiones relativas al ingreso, ascenso o responsabilidad disciplinaria son competencia del Ministerio de Defensa». Vemos en tales afirmaciones ciertas similitudes con lo apreciado por el TEDH.

También son habituales las críticas que en este sentido dirigen a la jurisdicción militar las asociaciones profesionales de militares y guardias civiles ${ }^{12}$, que, aunque legalmente no poseen una naturaleza representativa colectiva (véanse los arts. 38 de la Ley Orgánica 11/2007, de 22 de octubre, reguladora de los derechos y deberes de los miembros de la Guardia Civil, y 40 de la Ley Orgánica 9/2011, de 27 de julio, de derechos y deberes de los miembros de las Fuerzas Armadas), considero que debieran ser oídas si quiere configurarse un modelo de jurisdicción militar que goce de la confianza de sus principales justiciables. No debe obviarse lo que reiteradamente ha manifestado el TEDH en relación con el art. 6.1 CEDH, en el sentido de que «el punto de vista del enjuiciado, sin ser decisivo, sí resulta importante» ${ }^{13}$. La también imprescindible participación de los ejércitos en la confección de los textos legales necesarios se operaría a la hora de redactar los pertinentes anteproyectos y, tanto legal (art. 561 LOPJ) como doctrinalmente, resulta innegable la aportación que pueda realizar el CGPJ.

\section{RAZONES ESPECÍFICAS PARA UNA NUEVA JURISDICCIÓN MILITAR}

Más allá de lo apuntado por el propio legislador, considero que existen motivos mucho más trascendentes para una nueva configuración de la

Así queda expuesto en varios artículos de D. Mariano Casado Sierra (2015; 2014; 2009), secretario general de la Asociación Unificada de Militares Españoles (AUME) y miembro del Observatorio de la Vida Militar, o por parte de la Asociación de Tropa y Marinería Española —ATME- (2018).

Las asociaciones profesionales de guardias civiles, por su parte, centran sus reivindicaciones en la exclusión del Instituto Armado del ámbito penal castrense. Así, la Unión de Guardias Civiles _-UGC- (2017) o la Asociación Unificada de Guardias Civiles -AUGC- $(2019 ; 2016)$.

13 Entre otras, las SSTEDH de 24 de mayo de 1989, caso Hauschildt contra Dinamarca, ap. 48; de 22 de abril de 1994, caso Saraiva de Carvalho contra Portugal, ap. 35; de 20 de mayo de 1998, caso Gautrin y otros contra Francia, ap. 58, o de 25 de septiembre de 2001, caso Sahiner contra Turquía, ap. 44. 
jurisdicción militar. Distingue Matamoros Martínez (2016:3-7) entre razones formales, técnicas y de oportunidad de esta reforma, identificando las primeras con las referidas previsiones legales en pro de la reforma; las técnicas serían la introducción de la doble instancia penal, la efectividad del principio acusatorio, el refuerzo de la garantía de independencia y la actualización de la oficina judicial y del papel del secretario relator, y las de oportunidad, la acomodación de la estructura jurisdiccional a la realidad de las Fuerzas Armadas y la eficiencia en la persecución de los delitos.

Sin restar importancia a la necesaria actualización de la oficina judicial y del papel del secretario relator o a la efectividad del principio acusatorio, dentro de las denominadas "técnicas» considero ineludibles la instauración de la doble instancia penal y el refuerzo de la independencia judicial, debido a su reconocimiento en diversos tratados internacionales suscritos por España (así, arts. 14.5 PIDCP y 2 Protocolo VII al CEDH y 14.1 PIDCP y 6.1 CEDH, respectivamente), lo que hace inaplazable su implantación.

Todas estas modificaciones han de partir, no obstante, de las denominadas por dicho autor como razones de oportunidad, y que conectan con lo que en este trabajo se ha expuesto como principios o elementos diferenciales de la jurisdicción militar, pues es su función vinculada a las misiones de las Fuerzas Armadas la que justifica la particular caracterización de la jurisdicción militar y la que, al mismo tiempo, ha de presidir la configuración de esta.

\section{GARANTÍAS DE INDEPENDENCIA E IMPARCIALIDAD}

En lo referido a la implantación de la doble instancia penal me remitiré a lo señalado por varios autores ${ }^{14}$, centrándome aquí en la consideración de las garantías de independencia e imparcialidad tal y como han quedado expuestas en el análisis anterior de la jurisprudencia del TEDH. Y es que es en relación con estas cuestiones donde surgen un buen número de las críticas hacia la actual jurisdicción militar española ${ }^{15}$.

14 Entre otros, Egido Trillo-Figueroa (2008) y, recientemente, Marín Castán (2018).

15 Así, en relación con el régimen de ascensos, Parada Vázquez (1992: 41), Ramírez Sineiro (1994: 160-166), Millán Garrido (1989: 119) o Hernández Montiel (1990: 183), todos ellos miembros del Cuerpo Jurídico Militar -o de sus precedentes Cuerpos Jurídicos de los Ejércitos-, hoy en situaciones distintas del servicio activo. Los dos primeros también se refieren a la duplicidad de funciones - judicial y asesora- de los miembros del Cuerpo Jurídico Militar. 
En primer lugar, en cuanto al modo de designación de los cargos judiciales militares, este ha experimentado un notable avance en pro de la independencia e imparcialidad tras la reforma operada por la Ley Orgánica 14/2015 (arts. 37, 47 y 54 LOCOJM). Así, la supresión de la terna que el Ministerio de Defensa elevaba al CGPJ para el nombramiento de los magistrados de la Sala V procedentes del Cuerpo Jurídico Militar equipara el nombramiento de estos al de los magistrados procedentes del turno de juristas de reconocido prestigio, con la única restricción de la procedencia del señalado cuerpo. Para el resto de nombramientos, aun cuando la competencia de estos recae igualmente en el Pleno del CGPJ — frente a la anterior del Ministerio de Defensa-, es la Sala de Gobierno del Tribunal Militar Central la que, haciendo uso de una discrecionalidad que, a mi modo de ver, el art. 25.2. ${ }^{\circ}$ LOPM $^{16}$ no establece, determina si producida una vacante en un órgano judicial militar esta debe ser objeto de convocatoria o no, o en qué momento; determinación no exenta de implicaciones ya que condiciona los posibles concurrentes. Además, tales vacantes, al estar incluidas en la relación de puestos militares del Cuerpo Jurídico Militar ${ }^{17}$, quedan sometidas de facto a las vicisitudes y necesidades de tal relación, a pesar de la existencia de una ley de planta ${ }^{18}$ que determina la existencia - y, en buena lógica, dotación- de los órganos judiciales castrenses. En definitiva, la reforma legal operada ha

16 «A la Sala de Gobierno del Tribunal Militar Central, con la composición señalada en el artículo 42 de la Ley Orgánica de la Competencia y Organización de la Jurisdicción Militar y las funciones que dispone el artículo 35 de la misma, le corresponde: $[\ldots]$

2. Solicitar el anuncio y provisión de las vacantes que se produzcan en los órganos judiciales militares».

17 Ley 39/2007, de 19 de noviembre, de la Carrera Militar. "Artículo 17 Plantillas orgánicas y relaciones de puestos militares.

1. Las unidades, centros y organismos del Ministerio de Defensa tendrán definida su plantilla orgánica. Dicha plantilla es la relación cuantitativa y cualitativa de puestos de su estructura necesarios para estar en condiciones de cumplir los cometidos que tengan asignados.

2. A partir de las plantillas orgánicas y los grados de cobertura que se determinen en función del planeamiento de efectivos, se establecerán las relaciones de puestos militares en las que se especificarán, en todo caso, la descripción de cada puesto, su asignación por cuerpos y escalas, empleos y especialidades, sus retribuciones complementarias y las condiciones y requisitos para su ocupación. En dichas relaciones figurarán los que puedan ser cubiertos por personal en reserva».

18 Ley 44/1998, de 15 de diciembre, de Planta y Organización Territorial de la Jurisdicción Militar. 
conferido al Pleno del CGPJ la competencia para nombrar los cargos judiciales militares, pero, de facto, es la Sala de Gobierno del Tribunal Militar Central, con sometimiento a las plantillas fijadas por el Ministerio de Defensa, la que decide o no convocarlos.

Otra de las cuestiones que, como hemos visto, ha sido abordada por el TEDH es la designación de jueces ad hoc y sin formación legal. Los arts. 36, 39, 46 y 49 LOCOJM establecen la designación de vocales militares, pertenecientes a los Cuerpos Generales de los Ejércitos o a la Guardia Civil —según los casos-, para formar parte de los órganos judiciales militares. Fernández Segado (1992: 23) ha valorado positivamente esta incorporación al considerar que «la presencia de profesionales de la Milicia en los órganos judiciales castrenses no sólo encuentra su respaldo constitucional en el art. 125 de nuestra Norma suprema, sino que, además, los profesionales de las Armas que integren un Tribunal castrense se encuentran especialmente capacitados para juzgar las cuestiones de hecho». Pero ya vimos cómo en el caso Morris el TEDH estimó que esa participación no era asimilable a la de un jurado civil, dado el riesgo de presión al que puede estar sometido un militar al enjuiciar cuestiones referidas a su condición, añadiendo la falta de formación jurídica y de garantías adicionales que salvaguarden su independencia. Respecto a esas garantías adicionales cabría valorar si la otorgada por el art. 9 LOCOJM $^{19}$ puede estimarse suficiente a los efectos de cumplimentar las exigencias del $\mathrm{TEDH}$, teniendo en cuenta que dichos militares siguen, antes, durante y después de su participación en el tribunal, perteneciendo a una unidad militar, sometidos a informes y evaluaciones y al régimen disciplinario castrense.

En lo referente al estatuto jurídico de los jueces militares propiamente dichos (en una acepción amplia, que incluye tanto a jueces togados como vocales togados y auditores presidentes), aparece caracterizado por la pertenencia de estos a un cuerpo militar (el Cuerpo Jurídico Militar), excepción

19 «Las personas a que se refiere el artículo anterior, que se consideren perturbadas en su independencia, lo pondrán en conocimiento del Consejo General del Poder Judicial a través de la Sala de Gobierno del Tribunal Militar Central, dando cuenta de los hechos al Juez o Tribunal competente para seguir el procedimiento adecuado, sin perjuicio de practicar por sí mismos las diligencias estrictamente indispensables para asegurar la acción de la justicia y restaurar el orden jurídico.

A los miembros de Sala de lo Militar del Tribunal Supremo les será de aplicación lo dispuesto a estos fines en la Ley Orgánica del Poder Judicial.

El Ministerio Fiscal y en particular la Fiscalía Jurídico Militar, por sí o a petición de aquéllos, promoverá las acciones pertinentes o instará, según los casos, lo que proceda en defensa de la independencia de los órganos judiciales militares». 
hecha de los magistrados de la Sala V del TS. Además de la ya comentada garantía del art. 9 LOCOJM, esta misma ley establece algunos postulados relativos a su estatuto jurídico, en particular en lo atinente a los nombramientos, ceses, suspensiones, incompatibilidades y régimen disciplinario (arts. 8, 37, 47, 54, 65 a 68, 117 a 124 y 128 a 148), en términos semejables a sus homólogos civiles. Pero en su condición de militares, estos jueces también están sujetos al régimen disciplinario castrense y a todo un conjunto de normas que rigen las evaluaciones, ascensos, destinos, formación, retribuciones y, en suma, la carrera propia de los militares, aunque con alguna particularidad.

Así, en el relevante aspecto del régimen disciplinario, asumen el apuntado doble sometimiento: al régimen disciplinario que podemos denominar judicial ${ }^{20} \mathrm{y}$ al militar propiamente, si bien la competencia para la imposición de las sanciones por este régimen corresponde únicamente a los auditores presidentes y a la Sala de Gobierno del Tribunal Militar Central (art. 28 Ley Orgánica 8/2014, de 4 de diciembre, de Régimen Disciplinario de las Fuerzas Armadas, LORDFAS), siendo, a su vez, preceptivo que el instructor de los expedientes sea otro miembro del Cuerpo Jurídico Militar con funciones judiciales (art. 49.3 LORDFAS).

Uno de los elementos caracterizadores del estatuto del personal militar es su sometimiento a evaluaciones. Estas se encuentran previstas en los arts. 85 a 87 de la Ley 39/2007, de 19 de noviembre, de la Carrera Militar (LCM) y reguladas por el Reglamento de evaluaciones y ascensos en las Fuerzas Armadas y sobre el acceso a la condición de militar de carrera de militares de tropa y marinería, aprobado por Real Decreto 168/2009, de 13 de febrero, y sus disposiciones de desarrollo. Tales evaluaciones pueden llevarse a cabo, en lo que aquí interesa, "para determinar su aptitud para el ascenso al empleo superior, para seleccionar los asistentes a cursos y para comprobar la existencia de insuficiencia de facultades profesionales o de condiciones psicofísicas» (art. 85 LCM), y en ellas «se analizarán las circunstancias de los interesados en los aspectos de su personalidad, condiciones psicofísicas, competencia y actuación profesional relacionados con el objeto de la misma», es decir, en el caso de los jueces militares, incluirán una valoración de su actuación profesional como tales. Dentro de los elementos determinantes en tales evaluaciones se encuentra el historial militar, en el que se incluye la denominada colección de informes personales. Estos informes personales de calificación son «la valoración objetiva de unos conceptos predeterminados que permitan apreciar las cualidades, méritos, aptitudes, competencia y forma de actuación

20 Capítulo II, título IX, de la LOCOJM. 
profesional del militar» (art. 81 LCM) y son emitidos anualmente de forma ordinaria o de manera extraordinaria en determinadas circunstancias. En el caso de los jueces militares, tales informes son emitidos por los auditores presidentes del respectivo territorio, y respecto de los auditores presidentes, jueces togados centrales o vocales del Tribunal Militar Central, por el presidente de dicho Tribunal. Además, dentro de dicho historial militar se recogen vicisitudes tales como los destinos ocupados - a los que se asigna una puntuación-, recompensas concedidas, misiones en el exterior o la formación tanto militar como civil.

En relación con los destinos, ya hemos expuesto cómo se asignan los que corresponden a jueces militares, pero en los que puedan ocupar en su condición de militares se encuentran sometidos a la regulación establecida tanto en la LCM como en el Reglamento de destinos del personal militar profesional, aprobado por Real Decreto 456/2011, de 1 de abril. Ya señalamos cómo la denominada relación de puestos militares condicionaba de facto la cobertura de los puestos de jueces militares. Dicha relación especifica, «en todo caso, la descripción de cada puesto, su asignación por cuerpos y escalas, empleos y especialidades, sus retribuciones complementarias y las condiciones y requisitos para su ocupación» (art. 17.2 LCM), es decir, a la vista de tal regulación, cabe preguntarse si tal relación de puestos puede establecer determinadas condiciones o requisitos para la ocupación de los puestos de jueces militares. Por otro lado, la mayor parte de los puestos del Cuerpo Jurídico Militar son asignados por el procedimiento de libre designación, lo que, según el art. 100.2 LCM, supone que «precisan condiciones profesionales y personales de idoneidad, que apreciará discrecionalmente la autoridad facultada para concederlos». Esa caracterización pudiera ser vista con recelo por los jueces militares que posteriormente hayan de verse obligados a concurrir a alguno de esos puestos.

En lo relativo a la formación, vimos cómo el TEDH valoraba positivamente que los jueces militares recibieran una misma formación que sus homólogos civiles. En nuestro país, si bien todos los jurídicos militares, al igual que los miembros de la carrera judicial, han de ser licenciados/graduados en Derecho y superar un exigente proceso selectivo y un posterior curso de formación inicial, la formación continua a lo largo de sus carreras resulta marcadamente diferente. Solo recientemente se ha dado acceso a los jueces militares a algunas de las actividades formativas que, organizadas por el CGPJ, son las propias de los miembros de la carrera judicial. Con carácter general la formación de los jueces militares es la propia del Cuerpo Jurídico Militar, sometida a la regulación de la enseñanza militar — título IV LCM y Real Decreto 339/2015, de 30 de abril-, correspondiendo su definición, admisión y determinación de los criterios de evaluación a autoridades administrativas. Por otro lado, la formación tanto 
militar como civil es objeto de valoración en las evaluaciones para el ascenso, con la ponderación cuantitativa establecida en las pertinentes instrucciones administrativas. No obstante, dentro de la civil únicamente son consideradas aquellas que conducen a la obtención de un título igual o superior al exigido en el ingreso (es decir, licenciatura/grado, máster o doctorado), con una significativamente menor valoración si atendemos al número de créditos y prescindiendo de la obtenida a través del CGPJ u otras instituciones formativas.

En el ámbito de las retribuciones y del régimen de acción social, los jueces militares se encuentran igualmente sometidos al régimen propio del personal militar, siendo la ya mencionada relación de puestos militares la que establece las cuantías de las retribuciones complementarias de esos puestos. La asignación a los jueces militares, en su caso, del complemento de dedicación especial (análogo al complemento de productividad de los funcionarios públicos) corresponde al subsecretario de Defensa, facultad que tiene delegada en el auditor presidente del Tribunal Militar Central. La misma naturaleza administrativa, tanto en su régimen como en las autoridades responsables de su otorgamiento, corresponde a la acción social, que comprende cuestiones tales como convocatorias de becas para hijos, acceso a residencias o apartamentos vacacionales, ayudas para necesidades sanitarias o de cuidados médicos u ortopédicos, ayudas para la adquisición o alquiler de vivienda o disfrute de viviendas militares, etc.

Finalmente, en cuanto a la imparcialidad de los jueces militares, se trata de una materia significativamente afectada por la jurisprudencia del $\mathrm{TEDH}^{21}$, que dio lugar a la reforma de la LOCOJM llevada a cabo por la Ley Orgánica 9/2003, de 15 de julio. La adecuación operada en la organización de la jurisdicción militar cumplimentó las exigencias de esta garantía sin perjuicio, como acertadamente señala Gil Honduvilla (2017), de que existan determinadas afectaciones a esta a causa de la situación expuesta de la falta de convocatoria de determinados destinos judiciales militares legalmente previstos.

\section{PROPUESTAS PARA LA ADOPCIÓN DE UN NUEVO MODELO DE JURISDICCIÓN MILITAR}

Sentadas las premisas sobre las que entiendo que debe asentarse el nuevo modelo de jurisdicción militar, me atrevo a apuntar cuáles pueden ser algunas

21 SSTEDH de 28 de octubre de 1998, caso Castillo Algar, y de 25 de julio de 2002, caso Perote Pellón, Decisión de 2 de marzo de 2000, caso Garrido Guerrero, todos ellos contra España. 
de las notas de dicho modelo, propuesta que — como ya señalé- pretende propiciar un debate que conduzca a alcanzar la mejor de las soluciones.

A la vista de lo expuesto, considero que la mayor transformación ha de operarse en lo relativo al estatuto jurídico de los jueces militares, con el fin de lograr una nítida desvinculación del Ministerio de Defensa durante el tiempo que ejerzan su función de tales y establecer determinadas garantías para el caso de que retornen a la carrera puramente militar. Disiento, sin embargo, de las afirmaciones de Canosa Usera (1995: 351) referidas a que «el sentido pleno del principio de exclusividad exige, no solo de los órganos juzgadores, sino también de sus miembros que se dediquen por entero a lo largo de su carrera en el cuerpo único de Jueces a la aplicación de la ley y sólo a la aplicación de la ley». De hecho, tal aserto no se corresponde con las funciones que hasta ahora han venido asumiendo los miembros de la carrera judicial en ocupaciones de Registro Civil, pero tampoco con las que como letrados o inspectores asumen habitualmente en el CGPJ, por no hablar de las que pueden abordar desde la no poco común situación de excedencia o servicios especiales. Ya la Ley Orgánica 5/1997, de reforma de la LOPJ, trató de conciliar esos cambios de situación administrativa con la imparcialidad judicial, especialmente a través de la previsión de la causa de abstención y recusación que hoy recoge el apartado 16..$^{\circ}$ del art. 219 LOPJ, al que sería bueno se remitiera la LOPM, con el fin de limitar los olvidos del legislador que producen la disparidad entre ambas normas (véase el art. 53 LOPM). No resulta admisible que se establezca una presunción de falta de imparcialidad generalizada en los jueces militares por el hecho de alternar puestos administrativos y jurisdiccionales en su carrera, las dudas o sospechas habrán de alcanzar «una consistencia tal que permita afirmar que se hallan objetiva y legítimamente justificadas» (SSTC 162/1999, de 27 de septiembre; 140/2004, de 13 de septiembre; 26/2007, de 12 de febrero; 60/2008, de 26 de mayo, y 47/2011, de 12 de abril).

No obstante, sería positivo establecer una situación administrativa específica o el paso de los jueces militares a servicios especiales durante el ejercicio de su condición de tales. Ello no supone una pérdida de la condición de militares, pero sí una desvinculación administrativa del Ejecutivo, de manera que su régimen estatutario durante dicho ejercicio sería el propio de los miembros de la carrera judicial con aplicación en lo relativo a ceses, comisiones, régimen disciplinario, formación, permisos, retribuciones o acción social. Ese acceso a la nueva situación podría regirse por la necesidad de superación de una determinada formación o proceso selectivo que, tomando en consideración los méritos logrados en el ejercicio de la función jurídico-militar, debería ser establecido y regido por el CGPJ. 
La cuestión que mayor dificultad plantea es - a mi juicio- la de la carrera militar de esos jueces. Al respecto pudieran seguirse dos alternativas: bien que esta quede suspendida como sucede con quienes actualmente pasan a las situaciones de excedencia o servicios especiales, bien que los procesos de evaluación para los ascensos del Cuerpo Jurídico Militar incorporen la valoración de esa especifica situación de los jueces militares y prescindan de los informes personales de calificación, de difícil justificación respecto de quienes ejercen funciones judiciales. No se trata de un supuesto extraño, pues los destinos que han venido ocupando miembros del Cuerpo Jurídico Militar como letrados del Tribunal Supremo (hoy de su Gabinete Técnico), han oscilado — según la norma en ese momento vigente — entre las consideraciones de situación de servicio activo y servicios especiales, entre la calificación como destino a efectos del tiempo de servicio necesario para el ascenso (sentencia de la Audiencia Nacional, Sala de lo Contencioso-Administrativo, Sección 5. a , de 10 de noviembre de 2016) o negando este (sentencias de la Audiencia Nacional, Sala de lo Contencioso-Administrativo, Sección 5. a, de 12 de julio de 2006 y de 25 de abril de 2007), lo que pone de manifiesto el margen de discrecionalidad de que dispone la Administración militar a la hora de regular esta materia.

En lo referido a la organización, las señaladas notas de celeridad y agilidad que deben caracterizar a la jurisdicción militar ${ }^{22}$ podrían mejorarse notablemente a través de la instauración de jueces unipersonales, con mayor proximidad a las unidades militares desplegadas, y que también facilitaría, como seńala Egido Trillo-Figueroa (2008: 34), la implantación de la segunda instancia. La creación de esos órganos habría de ir acompañada de la implementación de procesos dotados de mayor sumariedad, al modo de los establecidos para el enjuiciamiento rápido de determinados delitos o para el juicio sobre delitos leves que prevé la LECR. Estos juzgados asumirían también la instrucción de aquellos procedimientos que, en atención únicamente a la gravedad o complejidad del delito en cuestión y no al empleo militar del investigado, exigieran la atribución de instrucción y fallo a dos órganos diferentes, siempre en el caso de que la primera no fuera atribuida al fiscal jurídico militar, en cuyo caso actuarían como jueces de garantías. También se les encomendaría la resolución de los procedimientos de habeas corpus y el conocimiento de cuestiones disciplinarias a las que luego se hará referencia.

Además, esa mayor proximidad de los jueces a las unidades y consiguiente reducción de las demarcaciones de los actuales juzgados togados haría posible la configuración de un sistema de guardias y suplencias entre ellos que

22 También Escalada López (2007: 30-31) hace referencia a esta nota caracterizadora de la jurisdicción militar. 
hiciera efectiva la permanente disponibilidad de los órganos judiciales militares. Tal disponibilidad no puede lograrse mediante una mera proclamación normativa de esta, pues resulta inverosímil que un mismo órgano judicial pueda estar de guardia las 24 horas del día y los 365 días del año y que, además, sea capaz de atender de forma efectiva las eventualidades que puedan acaecer en demarcaciones que de facto se extienden hasta quince provincias. También habría de disponerse los medios y procedimientos necesarios para que estos jueces pudieran actuar en los lugares en que despliegan nuestras Fuerzas Armadas en el exterior, de ser ello necesario. A todos estos efectos y a los apuntados en la STEDH del caso Miroshnik contra Ucrania, resultaría más eficaz y acorde con la necesaria independencia del órgano que los juzgados militares se integraran en las instalaciones y se valieran de los medios del resto de órganos integrantes del Poder Judicial, tales como institutos de medicina legal, oficinas de asistencia a víctimas, equipos psicosociales, aplicaciones informáticas de apoyo al proceso judicial, etc. Asimismo, el personal auxiliar de los órganos judiciales militares — sin incluir aquí a los secretarios relatores - debería ser el propio del Poder Judicial, por razones de formación y adecuación a sus funciones.

En segundo lugar, se establecerían juzgados igualmente unipersonales que fallarían aquellos delitos que exigen una atribución a diferentes órganos de las fases de instrucción y plenario. También asumirían estos órganos la resolución de recursos frente a resoluciones de los jueces togados y la mayor parte de los recursos contencioso-administrativos.

Finalmente, se constituiría un único tribunal, compuesto por dos salas diferenciadas: una encargada del enjuiciamiento y fallo de aquellos delitos más graves y otra para los recursos de apelación frente a resoluciones de los jueces descritos anteriormente. En este último podría integrarse personal de los Cuerpos Generales de los Ejércitos, la Armada o la Guardia Civil, pero siempre que se trate de personal en reserva que se mantenga desvinculado de la carrera militar.

Este mayor número de órganos judiciales castrenses se llevaría a cabo, sin embargo, con un menor número de jurídicos militares al actualmente establecido en la LOCOJM. Las leyes vigentes prevén un total de cincuenta jueces militares (treinta entre presidentes y vocales de cada uno de los seis tribunales militares y un total de veinte jueces togados — centrales o territoriales-). Considerando una composición de seis miembros en el tribunal militar (tres en cada una de las salas) y la constitución de hasta veintiséis juzgados militares que podemos denominar de instrucción (a razón aproximada de uno cada dos provincias, lo cual deberá adecuarse al despliegue de las unidades militares), restarían hasta doce integrantes del Cuerpo Jurídico Militar que podrían 
constituirse en jueces que podemos denominar penales, lo que supone más del doble de los actuales tribunales militares territoriales.

Esta nueva organización jurisdiccional persigue, como señalaba, una mayor proximidad del órgano judicial con las unidades militares y una reducción del ámbito territorial de actuación de los jueces de primer nivel, lo que permitiría una actuación más inmediata de estos en el sentido tanto temporal como espacial. Ello posibilitaría la asunción por tales jueces de nuevas competencias que, a mi juicio, aportarían garantías para los derechos y libertades de los militares. Así, como ya apuntara Calvo Prieto (1992: 3), podrían judicializarse «al menos las faltas graves, con atribución de su instrucción a los Jueces Togados Militares Territoriales, siendo su fallo por otro Juez, distinto, y mediante unos recursos de apelación ante el Tribunal Militar Territorial competente», lo que a juicio del autor aportaría un doble beneficio: «[...] una agilidad superior en cuanto a su tramitación similar a los actuales "juicios rápidos", con sentencia incluso "in voce" cuando procediese, y por otro lado, amén de las mayores garantías si cabe para el justiciable, limitar muchos recursos de casación ante la Sala V del Tribunal Supremo». Otra posible ampliación podría incidir en el control de las sanciones privativas de libertad —al menos, en su ejecución - al modo de lo que sucede en el derecho alemán ${ }^{23}$, y que vendría a cerrar el debate sobre la adopción de medidas privativas de libertad por autoridades administrativas y sin posibilidad de una efectiva tutela judicial respecto de su ejecución inmediata ${ }^{24}$.

\section{Bibliografía}

Alaíz Villafáfila, C. M. (1992). El ámbito estrictamente castrense como marco constitucional de la competencia de la jurisdicción militar en tiempo de paz. Cuadernos de Derecho Judicial/Monografias, 4, 179.

23 Las medidas disciplinarias privativas de libertad o sanciones de cierta entidad han de ser confirmadas o adoptadas, según los casos, por un órgano judicial, como señalan Jiménez Vara (2018: 273-276) y Pau Echave-Sustaeta (2017: 279-292).

24 En mi trabajo (2014. La inmediata ejecutividad de las sanciones disciplinarias militares y el derecho a la tutela judicial efectiva, Revista General de Derecho Administrativo, 36) ya analicé la incidencia del derecho a la tutela judicial efectiva sobre la proclamación de la inmediata ejecutividad de las sanciones disciplinarias militares, manifestando mi opinión contraria al reconocimiento generalizado de esa facultad por parte de los mandos sancionadores. 
Asociación de Tropa y Marinería Española, ATME (2018). Las asociaciones de militares presentan sus demandas a partidos políticos y sociedad civil ante el menosprecio del ministerio de Defensa. Atme.es, 6-4-2018. Disponible en: https://bit.ly/2MuMpj7.

Asociación Unificada de Guardias Civiles, AUGC (2016). Expertos coinciden en señalar que la jurisdicción penal militar no tiene sentido en tiempos de paz. augc.org, 21-6-2016. Disponible en: https://bit.ly/3eCHbgX.

- (2019). AUGC lamenta la falta de consenso y valor en el Gobierno para dejar de aplicar el Código Penal Militar a los guardias civiles. augc.org, 7-2-2019. Disponible en: https://bit.ly/2MhsVy3.

Barcelona Llop, J. (1986). La organización militar: Apuntes jurídico-constitucionales sobre una realidad estatal. Revista de Administración Pública, 110, 55-106.

Blanquer Criado, D. (1996). Ciudadano y soldado. La Constitución y el servicio militar. Madrid: Civitas.

Calvo Prieto, D. (1992). El marco constitucional, organización y en especial competencias de la jurisdicción militar. Cuadernos de Derecho Judicial/Monografías, 4 (La jurisdicción militar).

Canosa Usera, R. (1994). Configuración constitucional de la jurisdicción militar. Revista del Poder Judicial, 34, 9-38.

(1995). A propósito de la independencia del juez militar (Comentario a la STC 204/1994 de 11 de julio). Revista del Poder Judicial, 37, 345-352.

Casado Sierra, M (2009). La asignatura pendiente de las Fuerzas Armadas. El País, 30-5-2009. Disponible en: https://elpais.com/diario/2009/05/30/opinion/1243634405_850215.html.

- (2014). Es posible otra jurisdicción militar. El Pais, 30-7-2014. Disponible en: https:// elpais.com/elpais/2014/07/28/opinion/1406573964_354624.html.

Casado Sierra, M (2015). Contrarreforma en la justicia castrense. El País, 11-6-2015. Disponible en: https:/elpais.com/elpais/2015/06/09/opinion/1433867964_663168.html.

Catalá Bas, A. (1999). La recepción de la jurisprudencia del Tribunal europeo de Derechos Humanos en la jurisprudencia del Tribunal Constitucional [tesis doctoral inédita]. Universitat de València.

Doig Díaz, Y. (2003). Jurisdicción Militar y Estado de derecho. Alicante: Publicaciones de la Universidad de Alicante.

Egido Trillo-Figueroa, B. J. (2008). La doble instancia penal en la jurisdicción militar: ideas para la reforma. Estudios jurídicos. Disponible en: http://www.cej-mjusticia.es/cej_ dode/servlet/CEJServlet.

Escalada López, M. L. (2007). Algunas reflexiones en torno a la jurisdicción militar. Revista General de Derecho Procesal, 12, 1-31.

Fairén Guillén, V. (1972). La potestad jurisdiccional. Revista de Derecho Judicial, 51-52, 45-84.

Fernández García, I. (2015). Los derechos fundamentales de los militares. Madrid: Secretaría General Técnica del Ministerio de Defensa.

Fernández Segado, F. (1992). El marco constitucional. La jurisdicción militar: su organización y competencia. Cuadernos de Derecho Judicial/Monografías, 4.

Gil García, O. (1999). La jurisdicción militar en la etapa constitucional. Madrid: Marcial Pons. 
Gil Honduvilla, J. (2017). La imparcialidad objetiva de los miembros de los tribunales militares. Comunicación presentada en VIII Jornadas sobre Jurisdicción Militar. Cuadernos Digitales de Formación, 50.

Gimeno Sendra, V., Moreno Catena, V. y Cortés Domínguez, V. (2003). Introducción al Derecho Procesal. Madrid: Colex.

González Reyes, J. M. (2011). Caracterización jurídica de las FAS como parte de la administración: El singular estatuto de la función pública militar como fundamento delimitador de derechos fundamentales y libertades públicas. Cuaderno práctico (Escuela Militar de Estudios Jurídicos), 5, 72-87.

Hauriou, M. (1976). La teoría de la institución y de la fundación. Madrid: Instituto de Estudios Administrativos.

Hernández Montiel, A. (1990). En torno a la nueva jurisdicción militar. Revista Española de Derecho Militar, 55, 175-186.

Higuera Guimerá, J. F. (1990). Curso de Derecho Penal Militar español. Barcelona: Bosch.

Jiménez Vara, J. F. (2018). Nota sobre la jurisdicción militar en la República Federal de Alemania. En Derecho militar y defensa nacional. Historia y perspectivas (pp. 273-276). Granada: Universidad de Granada.

Jiménez Villarejo, J. (1989). Algunos aspectos de la nueva organización de la Jurisdicción Militar. Revista Española de Derecho Militar, 53, 11-25.

Juanes Peces, A. (2014). Las causas de justificación en el Derecho Penal Militar. En B. López Lorca (coord.) y F. J. de León Villalba (dir.). Derecho Penal Militar (pp. 133-196). Valencia: Tirant lo Blanch.

López Garrido, D. (1983). La posición constitucional de las Fuerzas Armadas. Revista de Administración Pública, 100-102, 949-971.

López Lorca, B. (2011). Algunas reflexiones para la reforma de la Justicia militar. Seminario Permanente de Ciencias Sociales (SPCS) Documento de trabajo; 2011/15. Facultad de Ciencias Sociales de Cuenca.

López Ramón, F. (1987). La caracterización jurídica de las Fuerzas Armadas. Madrid: Centro de Estudios Políticos y Constitucionales.

Lorenzo Ponce de León, R. (2008). Impacto de la jurisprudencia del TEDH en la justicia militar británica y su interrelación con la de otros países del mundo anglosajón. Revista Española de Derecho Militar, 91, 85-140.

Marín Castán, F. (2018). Doble instancia penal y jurisdicción militar. En C. Gómez-Jara Díez (coord.). Persuadir y razonar: Estudios jurídicos en homenaje a José Manuel Maza Martín. Tomo I (pp. 955-992). Cizur Menor (Navarra): Thomson Reuters-Aranzadi.

Martín-Retortillo Baquer, L. (1995). La recepción por el Tribunal Constitucional de la jurisprudencia del Tribunal Europeo de Derechos Humanos. Revista de Administración Pública, 137, 7-30.

Matamoros Martínez, R. (2016). Líneas básicas para una reforma de la LO 4/1987, de 15 de julio, de la Competencia y Organización de la Jurisdicción Militar (LOCOJM). Comunicación presentada en Jornadas de especialistas en la jurisdicción militar, del Centro de Estudios Jurídicos. Disponible en: https://bit.ly/3driq7m.

Millán Garrido, A. (1989). Algunas consideraciones generales sobre la Ley Orgánica 4/1987. Revista Española de Derecho Militar, 53, 107-119. 
Mozo Seoane, A. (1995). Las Fuerzas Armadas y su Ordenamiento jurídico (una relectura del debate sobre el artículo 8 de la Constitución. Revista Española de Derecho Militar, 65, 609-629.

Parada Vázquez, R. (1992). Toque de silencio por la justicia militar. Revista de Administración Pública, 127, 7-43.

Pau Echave-Sustaeta, A. (2017). El Servicio Jurídico de la Defensa en la República Federal de Alemania. Revista Española de Derecho Militar, 106, 279-292.

Pérez Esteban, F. (1999). La unidad jurisdiccional y sus consecuencias en la jurisdicción militar. Revista del Poder Judicial, 55, 507-543.

Ramírez Sineiro, J. M. (1994). La estructura orgánica de la jurisdicción militar: consideraciones acerca de su constitucionalidad con arreglo a la doctrina del Tribunal Europeo de Derechos Humanos. Revista del Poder Judicial, 33, 151-167.

Romano, S. (2013). El ordenamiento jurídico (traducido por Sebastián Martín-Retortillo y Lorenzo Martín-Retortillo). Madrid: Centro de Estudios Políticos y Constitucionales.

Secretaría del Jefe de Estado Mayor de la Defensa (2017). Concepto de Empleo de las Fuerzas Armadas. Disponible en: https://bit.ly/3dn8VWR.

Unión Guardia Civil, UGC (2017). UnionGC y PSOE solicitan la no aplicación del Código Penal Militar a los Guardia Civiles. uniongc.org, 7-7-2017. Disponible en: https://bit. ly/2Xnr1lX. 